\title{
OCORRÊNCIA DE ANTICORPOS ANTI-Brucella ovis EM OVINOS DE SINOP E REGIÃO, MATO GROSSO, BRASIL
}

\author{
Tulio Geraldino Manhezzo ${ }^{1}$; Luciana Auxiliadora Viebrantz da Conceição ${ }^{2}$ e \\ Bruno Gomes de Castro ${ }^{3 *}$
}

\section{RESUMO}

Neste estudo, foi realizado um levantamento soroepidemiológico da brucelose ovina por Brucella ovis em ovinos em idade reprodutiva da região norte-matogrossense com os objetivos de verificar frequência e distribuição da infecção por $B$. ovis em propriedades rurais e analisar os possíveis fatores de risco associados à infecção. Foram investigadas 11 propriedades criadoras de ovinos, das quais foram coletadas 337 amostras de sangue de carneiros e ovelhas de quatro municípios da mesorregião do Alto Teles Pires e Sinop, Mato Grosso. Os soros foram examinados pela técnica de imunodifusão em gel de ágar. De acordo com as análises, $72,7 \%(\mathrm{n}=8)$ das propriedades apresentaram evidência sorológica de infecção por $B$. ovis, com uma frequência média de 13,9\% (I.C.99\%) de animais sororreagentes. Nas propriedades que higienizavam suas instalações com maior frequência e naquelas que realizavam criação no sistema extensivo, a soropositividade foi estatisticamente inferior $(\mathrm{p}<0,05)$. Assim, neste estudo preliminar, verificou-se que a ovinocultura na região norte-matogrossense ainda não é uma atividade econômica primária, o que leva a uma baixa produtividade e gera predisposição à ocorrência da brucelose ovina e outras enfermidades em decorrência da baixa tecnificação da atividade.

DESCRITORES: Brucelose; Brucella ovis; epidemiologia; imunologia.

\section{ABSTRACT}

Sero-epidemiological survey for Brucella ovis infection in sheep from Sinop and its surroundings, Mato Grosso State, Brazil

A sero-epidemiological survey was conducted to determine the prevalence and distribution of Brucella ovis infection in ovines from the northern region of Mato Grosso State, Brazil.

\footnotetext{
1. Discente de Medicina Veterinária da Universidade Federal de Mato Grosso, Campus Universitário de Sinop, Mato Grosso, Brasil;

2. Médica Veterinária autônoma;

3. Universidade Federal de Mato Grosso, Campus Universitário de Sinop, Mato Grosso, Brasil.
}

Autor para correspondência: Bruno Gomes de Castro, Avenida Alexandre Ferronato, 1200, Distrito Industrial, CEP 78557-267 Sinop, MT, Brasil. E-mail: castrobg@ufmt.br

Recebido para publicação em: 11/3/2015. Revisto em: 24/8/2015. Aceito em: 30/11/2015. 
The risk factors for the infection were also verified. 337 blood samples from rams and sheep of reproductive age from 11 sheep herds of four municipalities at Alto Teles Pires and Sinop mesorregion were investigated. All sera were examined by of immunodifusion in agar gel. From the total of examined herds, $72.7 \%(\mathrm{n}=8)$ of the farms presented at least one seropositive animal for Brucella ovis. The mean prevalence of seropositive animals was $13.9 \%$ (99\% CI). The seropositivity was lower in extensive productions and in herds where cleanliness was frequently observed $(\mathrm{p}<0.05)$. We conclude that the sheep industry in northern Mato Grosso State is still not a main economic activity, leading to low productivity and predisposition to the occurrence of ovine brucellosis and other diseases due to poor techniques applied in breeding.

KEY WORDS: Brucellosis; Brucella ovis; epidemiology; immunology.

A brucelose ovina, causada por Brucella ovis, comumente denominada epididimite dos carneiros, é uma doença contagiosa caracterizada por um quadro clínico de epididimite, abortamentos e mortalidade perinatal de cordeiros. Sua ação diminui a eficiência reprodutiva nos rebanhos e provoca elevadas perdas econômicas à ovinocultura (Azevedo et al., 2004).

No Brasil, a infecção por Brucella ovis foi descrita e diagnosticada pela primeira vez no Rio Grande do Sul, por meio de um estudo clínico em ovinos e confirmada por Blobel et al. (1972). Diversos outros autores vêm relatando, desde então, estudos de levantamento soroepidemiológico de anticorpos anti-B. ovis que apresentam frequência entre 7,5\% e 11,3\% (Alves et al., 2010; Clementino et al., 2007). Entretanto, são raros os estudos sobre a ocorrência da infecção em outras regiões do Brasil, não havendo referências a respeito da situação desta doença no rebanho ovino do estado de Mato Grosso.

O diagnóstico da epididimite infecciosa dos carneiros deve basearse na combinação do exame clínico e sua confirmação pelo isolamento da B. ovis do sêmen e/ou resultados positivos nas provas sorológicas (Martins et al., 2013). O diagnóstico clínico não é suficiente porque apenas $50 \%$ dos carneiros infectados com B. ovis apresentam epididimite. A confirmação do diagnóstico pode ser feita pelo cultivo em meios seletivos para isolamento da bactéria do sêmen de carneiros, de descargas vaginais e leite das ovelhas. No entanto, os métodos sorológicos indiretos são amplamente utilizados, sendo a imunodifusão em gel de ágar (IDGA) o método de triagem recomendado pela OIE (Pinheiro Junior et al., 2009).

Assim, este estudo preliminar objetivou realizar um levantamento soroepidemiológico de anticorpos anti- $B$. ovis em ovinos em idade reprodutiva em quatro municípios da região norte-matogrossense, bem como possíveis fatores de risco associados à infecção.

Para a realização deste estudo, foram utilizadas amostras de soro ovino do Banco de Soro do Laboratório de Doenças Infecciosas do Hospital Veterinária da UFMT Sinop, sendo processadas 337 amostras de sangue de ovinos, machos e fêmeas, em idade reprodutiva. Não foram utilizados 
machos castrados nem fêmeas jovens imaturas sexualmente por conta de sua pouca relevância no processo epidemiológico da transmissão da B.ovis.

A imunodifusão em gel de ágar (IDGA), técnica utilizada como prova de triagem, foi realizada no Laboratório de Doenças Infecciosas no Hospital Veterinário da UFMT Sinop. Foram utilizados kits produzidos pelo Instituto de Tecnologia do Paraná (TECPAR), sendo a técnica aplicada de acordo com as instruções do fabricante, utilizando-se antígeno de lipopolissacarídeos e proteínas de B. ovis, amostra Reo 198.

A caracterização da significância entre as diferenças observadas nas frequências de animais reativos segundo o sexo e a procedência e os aspectos relacionados a fatores de risco foram determinados por meio do Teste Exato de Fischer, pelo programa Biostat 5.0. O nível de significância adotado foi de 5\% (Martins et al., 2013).

De acordo com os dados verificados no presente levantamento, 8 das $11(72,7 \%)$ propriedades investigadas apresentaram um ou mais ovinos sororreagentes para $B$. ovis pelo teste de imunodifusão em gel de ágar.

Quando avaliada a frequência de animais soropositivos para a brucelose ovina por B. ovis, das 337 amostras, $47(13,9 \%)$ apresentaram resultado positivo na prova de triagem.

De acordo com os resultados obtidos, a frequência de brucelose ovina nos animais avaliados foi semelhante àquela observada nos estudos de Azevedo et al. (2004) e Nozaki et al. (2004). Nesses estudos foram verificadas as frequências de $11,3 \%$ em rebanho do estado do Rio Grande do Norte e $12 \%$ em São Paulo. A frequência verificada no presente estudo foi maior que a observada em diversos estudos de frequência da brucelose ovina no Brasil: Santos et al. (2013), em estudo realizado no estado da Paraíba, verificaram a frequência de 5,2\%; Silva et al. (2009), verificaram positividade de 3,2\% na Bahia e Rizzo et al. (2014) que verificaram 1,7\% de animais sororreagentes em São Paulo. A diferença observada nos variados estudos decorre, possivelmente, de características de criação e manejo que favorecem a morbidade do agente.

No que diz respeito à distribuição de animais soropositivos quanto ao gênero, foi verificada positividade na IDGA em 19 machos $(26,8 \%)$ e 28 fêmeas $(10,5 \%)$, não havendo, portanto, diferença significativa.

Desta forma, fica evidenciado que a ocorrência da brucelose ovina nos municípios se encontra dentro da média nacional. A frequência de animais sororreagentes por município pode ser verificada na Tabela.

No estado de Mato Grosso, principalmente em sua região médionorte, a colonização sulista é predominante em decorrência da emigração da população dos estados do Sul do Brasil na década de 1970. Consequentemente, a ovinocultura assumiu grande importância cultural e comercial, apesar do baixo nível tecnológico verificado nas propriedades visitadas. 
Tabela. Distribuição da frequência de ovinos soropositivos para Brucella ovis em municípios da região norte-matogrossense

\begin{tabular}{lr}
\hline Município & Frequência \\
\hline Sinop & $6,4 \% \%^{\mathrm{a}}$ \\
Sorriso & $12,5 \%^{\mathrm{a}}$ \\
Itaúba & $16,5 \%^{\mathrm{a}}$ \\
Santa Carmen & $18,6 \%^{\mathrm{a}}$ \\
\hline & $(\mathrm{p} \geq 0,05)$
\end{tabular}

Quanto à ovinocultura da região estudada, a quase totalidade do rebanho é composta por ovinos deslanados ou de pelo curto das raças Santa Inês, Dorper e seus mestiços, geralmente vindos de estados do Nordeste do Brasil ou do próprio estado. Além disso, verificou-se que, entre os ovinocultores visitados, é comum a compra de reprodutores sem nenhum tipo de controle para brucelose e outras enfermidades. Esta prática pode contribuir significativamente para a dispersão do agente entre as propriedades e para a frequência observada neste estudo, visto que soroprevalência similar foi reportada em estudos de rebanhos nordestinos (Silva et al., 2003; Azevedo et al., 2004).

Constatou-se também que $75 \%(n=6)$ das propriedades com animais positivos realizavam sistema de cria, recria e engorda e $25 \%(\mathrm{n}=2)$ criavam ovinos para subsistência. Todas as propriedades negativas (três) mantinham seus animais para cria, recria e engorda. Todavia, nenhuma propriedade praticava a ovinocultura com intuito exclusivo de reprodução dos seus animais, ou seja, para comercialização de reprodutores e seus subprodutos. Por conseguinte, cuidados com a sanidade do rebanho não constituem prioridade para este tipo de ovinocultor. Em trabalho semelhante, Clementino et al. (2007) também verificaram uma maior frequência de soropositivos para $B$. ovis em propriedades que criavam seus animais para subsistência.

Com relação à principal atividade praticada nas 11 propriedades visitadas, $37,5 \%$ das propriedades positivas tinham como principais atividades econômicas a bovinocultura e a agricultura; ao passo que $66,6 \%$ das propriedades negativas praticavam a bovinocultura como principal atividade econômica. Os percentuais evidenciam que a maior parte dos produtores visitados não tinha a ovinocultura como principal atividade, consequentemente eles não aplicavam todas as tecnologias disponíveis em suas criações, favorecendo o aparecimento de diversas enfermidades e deficiências nutricionais. Resultado semelhante foi verificado no estudo de Clementino et al. (2007) num estudo de fatores de risco associados à $B$. ovis em ovinos no semiárido paraibano.

Os dados obtidos apontam que, no que se refere ao sistema de criação, houve uma diferença estatística entre as propriedades positivas e negativas, 486 
visto que $100 \%$ das propriedades negativas realizavam sistema extensivo de criação e $62,5 \%$ das positivas criavam seus animais em sistema semi-intensivo e intensivo $(\mathrm{p}<0,05)$.

Desta forma, existe uma relação entre o sistema de criação e a ocorrência de brucelose ovina, pois o sistema extensivo dificulta a aglomeração dos animais, diminuindo a chance de dispersão do agente. Por sua vez, no sistema semi-intensivo ou intensivo há o aumento da densidade populacional associada à pressão de tecnificação visando ao aumento da produção, o que gera diminuição do bem-estar animal e, consequentemente, redução da resposta imunológica.

Além disso, foi verificada também diferença estatística no que se refere à metodologia de limpeza de instalações, uma vez que $87,5 \%$ dos produtores em cujos rebanhos havia brucelose ovina realizavam a higiene de suas instalações de modo semestral ou anual. Enquanto isso, $66,6 \%$ das propriedades negativas realizavam a limpeza dos equipamentos e instalações com frequência diária, semanal ou mensal $(\mathrm{p}<0,05)$. A higiene nestes ambientes deve ser executada de modo rotineiro para retirada de fômites, restos fetais e placentários para diminuir a possibilidade de disseminação do agente em questão, bem como de outros agentes infecciosos e parasitários.

A higienização e a limpeza das instalações são importantes para prevenir a disseminação da doença, visto que as ovelhas infectadas eliminam a B.ovis junto com as secreções vaginais, a placenta e o feto abortado (Grilló et al., 1999). Como as mucosas oral e nasal e a pele ferida são portas de entrada do agente (Bulgin et al. 1990), quando esses materiais permanecem nas instalações, podem contribuir para a disseminação da infecção nos rebanhos.

Neste estudo preliminar, verificou-se, portanto, que a ovinocultura na região norte-matogrossense ainda não é uma atividade econômica primária, o que leva a uma baixa produtividade e gera predisposição à ocorrência da brucelose ovina e outras enfermidades em decorrência da pouca tecnificação da ovinocultura. Ademais, a frequência de animais com anticorpos anti- $B$. ovis de $13,9 \%$ está acima de muitas regiões do país, mesmo sendo realizado o diagnóstico por uma técnica de triagem. Assim, devem ser realizados novos estudos sobre a sanidade dos ovinos da microrregião de Sinop e Alto Teles Pires, como também deve ser disponibilizada maior assistência técnica e científica para esses produtores rurais visando à melhoria de suas criações.

\section{REFERÊNCIAS}

1. Alves CJ, Figueiredo SM, Azevedo SS, Clementino IJ, Keid LB, Vasconcelos SA, Batista CSA, Rocha VCM, Higino SS. Detection of Brucella ovis in ovine from Paraíba State, in the northeast region of Brazil. Braz J Microbiol 41: 365-367, 2010.

2. Azevedo SS, Alves CJ, Alves FAL, Clementino IJ, Batista CSA, Azevedo AS, Ocorrência de anticorpos anti-Brucella ovis em ovinos procedentes de quatro municípios do estado do Rio Grande do Norte, Brasil. Agropecu Tec 25: 45-50, 2004. 
3. Clementino IJ, Alves CJ, Azevedo SS, Paulim LM, Medeiros KA. Inquérito soroepidemiológico e fatores de risco associados à infecção por Brucella ovis em carneiros deslanados do semiárido da Paraíba. Pesq Vet Bras 27: 137-143, 2007.

4. Grilló MJ, Marín CM, Barberán M. Experimental Brucella ovis infection in pregnant ewes. Vet Rec 144: 555-558, 1999.

5. Martins NEX, Almeida JDM, Silva MG, Sousa MG, Mathias LA, Almeida KS. Prevalência de anticorpos anti-Brucella ovis e anti-Brucella abortus em ovinos do município de Colinas, Tocantins, Brasil. Rev Patol Trop 42:147-160, 2013.

6. Nozaki CN, Megid J, Lima KC, Silva Júnior FF, Veloso CS. Comparação das técnicas de imunodifusão em gel de ágar e ELISA no diagnóstico de brucelose ovina em cabanhas da região centrooeste do estado de São Paulo. Arq Inst Biol 71: 1-5, 2004.

7. Pinheiro Junior JW, Oliveira AAF, Mota RA, Agottani JV, Jesus EM, Assis ST, Oliveira CZ. Ocorrência de ovinos sororeatores para Brucella ovis no Estado de Alagoas, Brasil. Vet Zootec 16: 500-508, 2009.

8. Rizzo H, Gregory L, Beraldi F, Carvalho AF, Pinheiro ES, Paulin LM. Ocorrência de anticorpos anti-Brucella ovis em ovinos com histórico de distúrbios reprodutivos no estado de São Paulo, Brasil. Arq Inst Biol 81: 99-106, 2014.

9. Santos FA, Higino SSS, Azevedo SS, Costa DF, Farias AEM, Alves FAL. Caracterização epidemiológica e fatores de risco associados à infecção por Brucella ovis em ovinos deslanados do semiárido paraibano. Pesq Vet Bras 33: 459-463, 2013.

10. Silva JBA, Feijó FMC, Teixeira MFS, Silva JS. Frequência de brucelose ovina causada por Brucella ovis em rebanhos do estado do Rio Grande do Norte, Brasil. Ciênc Anim 13: 51-54, 2003.

11. Silva NS, Barros IN, Dasso MG, Almeida MGÁR, Laborda SS, Anunciação AVM, Moreira ELT, Lima-Silva AE, Oliveira EMD. Detecção de anticorpos anti-Brucella ovis em ovinos do estado da Bahia. Rev Bras Saúde Prod Anim 10: 852-859, 2009. 